\title{
Excess perigestational folic acid exposure induces metabolic dysfunction in post-natal life
}

\author{
Elisa Keating ${ }^{1,2}$, Ana Correia-Branco', João R Araújo', Manuela Meireles', \\ Rita Fernandes ${ }^{1,3}$, Luísa Guardão ${ }^{4}$, João T Guimarães ${ }^{1,5,6}$, Fátima Martel $^{1}$ \\ and Conceição Calhau ${ }^{1,7}$
}

${ }^{1}$ Department of Biochemistry (U38-FCT), Faculty of Medicine, University of Porto, 4200-319 Porto, Portugal ${ }^{2}$ School of Biotechnology, Center for Biotechnology and Fine Chemistry, Portuguese Catholic University, 4200-072 Porto, Portugal

${ }^{3}$ Faculty of Nutrition and Food Sciences, University of Porto, 4200-465 Porto, Portugal

${ }^{4}$ Animal Facility, Faculty of Medicine, University of Porto, Porto, Portugal

${ }^{5}$ Department of Clinical Pathology, São João Hospital Center, 4200-319 Porto, Portugal ${ }^{6}$ ISPUP-EPIUnit, Institute of Public Health, University of Porto, 4050-600 Porto, Portugal

${ }^{7}$ CINTESIS - Center for Research in Health Technologies and Information Systems, University of Porto, 4200-319 Porto, Portugal

Correspondence should be addressed to E Keating Email keating@med.up.pt

\begin{abstract}
The aim of this study was to understand whether high folic acid (HFA) exposure during the perigestational period induces metabolic dysfunction in the offspring, later in life. To do this, female Sprague-Dawley rats (G0) were administered a dose of folic acid (FA) recommended for pregnancy (control, C, $2 \mathrm{mg} \mathrm{FA} / \mathrm{kg}$ of diet, $n=5$ ) or a high dose of FA (HFA, $40 \mathrm{mg} \mathrm{FA} / \mathrm{kg}$ of diet, $n=5$ ). Supplementation began at mating and lasted throughout pregnancy and lactation. Body weight and food and fluid intake were monitored in G0 and their offspring (G1) till G1 were 13 months of age. Metabolic blood profiles were assessed in $\mathrm{G} 1$ at 3 and 13 months of age (3M and 13M respectively). Both $\mathrm{G} 0$ and $\mathrm{G} 1$ HFA females had increased body weight gain when compared with controls, particularly 22 (G0) and 10 (G1) weeks after FA supplementation had been stopped. G1 female offspring of HFA mothers had increased glycemia at 3M, and both female and male G1 offspring of HFA mothers had decreased glucose tolerance at $13 \mathrm{M}$, when compared with matched controls. At 13M, G1 female offspring of HFA mothers had increased insulin and decreased adiponectin levels, and G1 male offspring of HFA mothers had increased levels of leptin, when compared with matched controls. In addition, feeding of fructose to adult offspring revealed that perigestational exposure to HFA renders female progeny more susceptible to developing metabolic unbalance upon such a challenge. The results of this work indicate that perigestational HFA exposure the affects long-term metabolic phenotype of the offspring, predisposing them to an insulin-resistant state.
\end{abstract}

\author{
Key Words \\ - dietary supplementation \\ - fetal programing \\ - folic acid \\ - metabolic syndrome \\ - pregnancy
}

(C) 2015 Society for Endocrinology Printed in Great Britain
Published by Bioscientifica Ltd
Journal of Endocrinology (2015) 224, 245-259 


\section{Introduction}

Folate is a generic term that designates a family of naturally occurring B-group vitamins derived from folic acid (pteroylglutamate, FA). FA is the fully oxidized and synthetic form of the vitamin used in supplements and in food fortification.

Folates are critical for the synthesis of purines and thymidylate, and for the generation of $S$-adenosylmethionine, a major methyl donor for DNA methylation processes, thus being essential compounds for cell division, for the epigenetic regulation of gene expression and, very probably, for fetal programing (Burdge \& Lillycrop 2010).

Besides this emerging role of folate in fetal programing, its importance during fetal development is unequivocal, as not only is low maternal folate intake associated with low birth weight and neural tube defects (NTDs), but also supplementation with FA during the periconceptional period reduces the incidence of such outcomes (Lucock 2000).

The effectiveness of FA in prevention of NTDs, and the inadequate compliance with FA supplementation by women of childbearing age resulted in the mandatory fortification of all enriched grain products with FA, in the USA, in the late 1990s. After the implementation of this policy, food fortification with FA was demonstrated to produce a general increase in serum folate levels (with concomitant decrease in homocysteine levels) in a US representative population sample (Pfeiffer et al. 2005) and to associate negatively with the prevalence of NTDs (Honein et al. 2001).

By January 2009, mandatory fortification with FA had been introduced in 52 countries worldwide. At that time, several EU countries permitted voluntary fortification, though none had implemented mandatory fortification (ESCO 2009), given the uncertainty about potential health hazards. In addition, the WHO currently recommends supplementation with $0.4 \mathrm{mg} /$ day of FA to women during pregnancy and the first 3 months post partum. As a result of all these public health policies, it is an emerging concern that FA intake may be exceeding the recommended upper levels, as has been recently described by several authors (Bailey et al. 2010, Hoyo et al. 2011, Gomez et al. 2013), with possible implications for serum FA levels (Brown et al. 2011).

To date, several studies report the programing effects of maternal FA supplementation on the offspring's health, mainly regarding autism (Castro et al. 2014), asthma, insulin resistance, and cancer (see Burdge \& Lillycrop
(2012) for a review). Results of studies of fetal programing of cancer by high FA exposure are somewhat conflicting. Indeed high intrauterine exposure to FA has been shown to increase mammary cancer risk in rodent offspring (Ly et al. 2011) while exerting protective effect against colorectal cancer risk (Sie et al. 2011).

Metabolic syndrome (MetS) is a condition of high and increasing prevalence worldwide that comprises a constellation of risk factors for cardiovascular disease and type 2 diabetes, such as central obesity, glucose intolerance, insulin resistance, dyslipidemia, and hypertension. MetS may be determined during fetal development due to nutritional, hormonal, or metabolic inputs from the mother (Sinclair et al. 2007, Xita \& Tsatsoulis 2010).

Based on this rationale and because there is a major gap in the current knowledge regarding the long-term metabolic effects of exposure to high doses of FA, the driving hypothesis of this work was as follows: does high FA supplementation during the perigestational period result in fetal programing of metabolic dysfunction during post-natal life?

To address this central question, we studied the effect of a perigestational supplementation of the diet of Sprague-Dawley (SD) female rats with high levels of FA on the long-term metabolic phenotype of their offspring.

\section{Materials and methods}

\section{Materials}

The study materials include D-fructose, D-glucose (SigmaAldrich); ketamine chlorhydrate (Imalgène 1000, Merial Portuguesa, Rio de Mouro, Portugal); medetomidine hydrochloride (Domitor, Orion Pharma, Orion Corporation, Espoo, Finland); treatment diets (control (C) or high folic acid (HFA), Research Diets, Inc., New Brunswick, NJ, USA); and standard diet (SAFE, Augy, France).

\section{Animals and diets}

All animal procedures were approved by the Directorate of Health and Animal Protection Services of the General Veterinarian Direction of the Portuguese Government. A diagram of the study design is depicted in Fig. 1.

Ten 7-week-old (225 $\mathrm{g}$ initial body weight) female SD CD rats (generation G0) (Charles River Laboratories, Barcelona, Spain) housed individually were divided into a control $(\mathrm{C}, n=5)$ and a high FA supplemented

Published by Bioscientifica Ltd. 


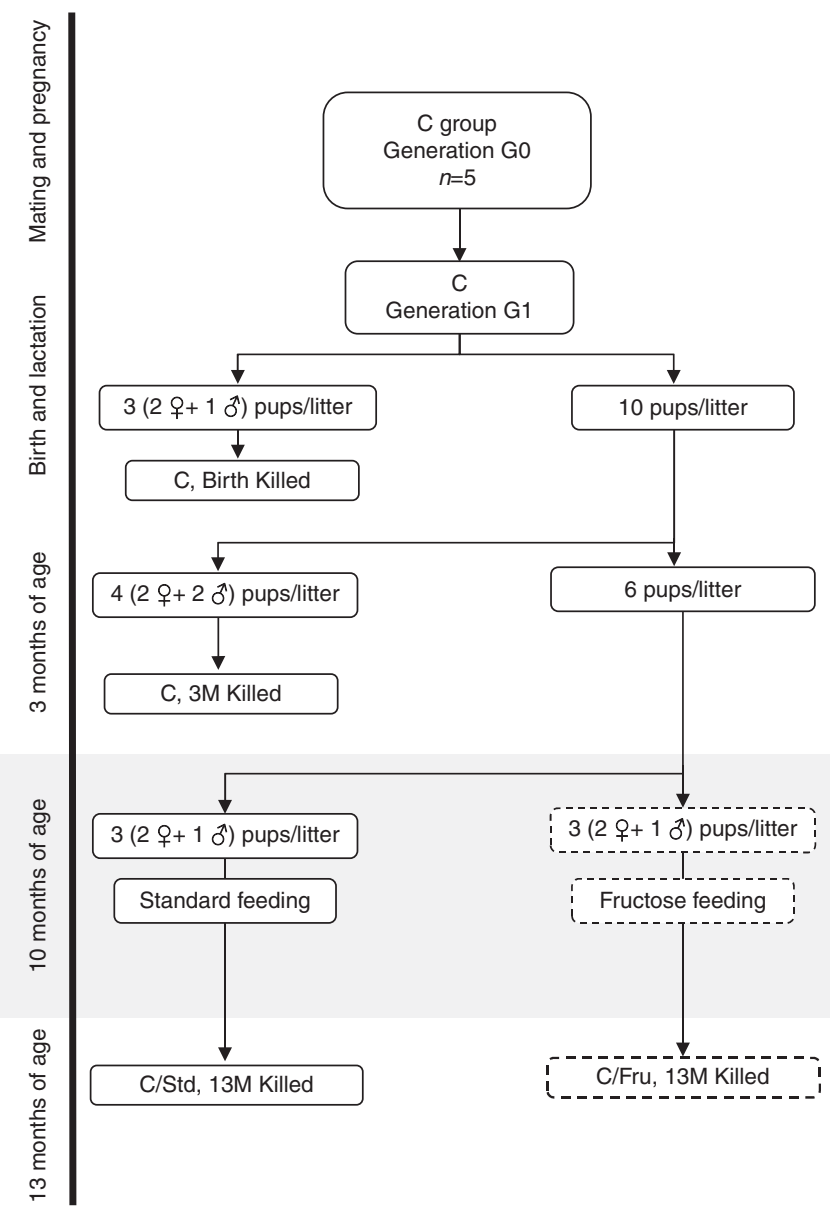

Figure 1

Diagram of the study design. In generation G0, control dams (C) were fed an adequate level of folic acid for pregnancy ( $2 \mathrm{mg} \mathrm{FA} / \mathrm{kg}$ of diet) and HFA dams were fed a FA-enriched diet containing $40 \mathrm{mg} \mathrm{FA} / \mathrm{kg}$ of diet. FA supplementation began during the mating period and lasted throughout pregnancy and lactation. Each generation G1 group (C and HFA) was divided, at 10 months of age, into a standard group fed the standard rat

(HFA, $n=5$ ) group. C dams were fed a diet containing an adequate level of FA for pregnancy ( $2 \mathrm{mg} \mathrm{FA} / \mathrm{kg}$ of diet) (Achon et al. 2000) and HFA dams were fed a FA-enriched diet containing $40 \mathrm{mg} \mathrm{FA} / \mathrm{kg}$ of diet. Diets were isocalloric, isollipidic, isoproteic, and isoglycidic (see Supplementary Table 1, see section on supplementary data given at the end of this article for diet composition). FA supplementation began during the mating period and lasted throughout pregnancy and lactation (perigestational period). Each G0 female was mated with a 7-week-old SD male and mating was confirmed by vaginal plug detection, which elicited estimation of gestational age and date of delivery.

On weaning, all mothers (G0) and pups (G1, both males and females) were given the same standard diet containing $0.5 \mathrm{mg} \mathrm{FA} / \mathrm{kg}$ of diet. This protocol ensured

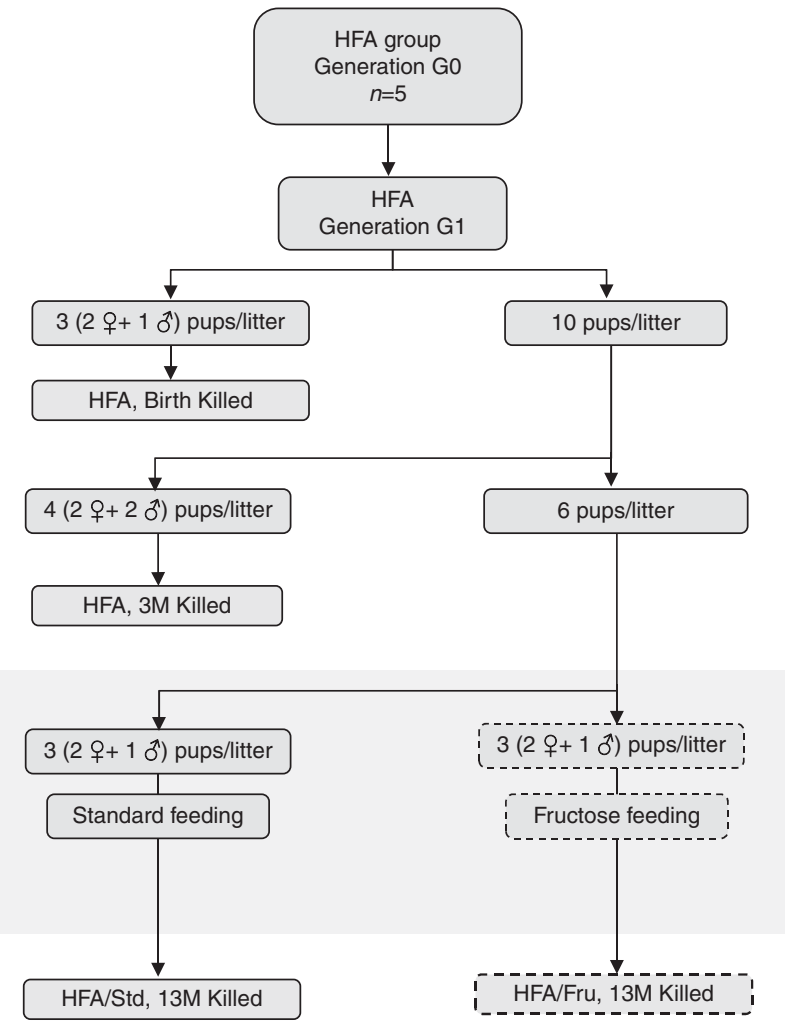

diet (C/Std and HFA/Std) and a high-fructose group, fed a high dose of fructose (10\% fructose in the drinking water) plus the standard rat diet (C/Fru and HFA/Fru). The animals were killed at birth, 3 months of age (3M), and 13 months of age (13M) for blood and tissue collection. The mean numbers of pups (total (females + males)) used per litter in each group are indicated.

that HFA and $\mathrm{C}$ diets were given only to G0, and so that G1 was exposed to HFA (or to C) diet only through placental feeding or lactation. Also the protocol approaches the situation of human pregnancy during which an extra-dose of FA is administered when compared with the nonpregnant state, when ingestion of FA is usually reduced.

Food and water were available and animals were allowed to eat and drink ad libitum. Animals were maintained in acclimatized rooms in $12 \mathrm{~h}$ light: $12 \mathrm{~h}$ darkness cycles.

The body weight and food and water ingestion of G0 females were measured daily from the beginning of the study till weaning and every 5-7 days thereafter. For G1 animals, (both males and females) body weight, feeding and drinking were measured every 3 days from birth till the end of the study.

Published by Bioscientifica Ltd 
In order to assess whether perigestational HFA supplementation rendered G1 animals more susceptible to metabolic dysfunction upon a metabolic challenge, each G1 group (C and HFA, both males and females) was divided, at 10 months of age, into a standard group fed the standard rat diet (C/Std and HFA/Std) and a high-fructose group, fed a high dose of fructose (10\% fructose in the drinking water) plus the standard rat diet (C/Fru and HFA/Fru).

For blood and tissue collection, the animals were killed by exsanguination under anesthesia with $50 \mathrm{mg} / \mathrm{kg}$ ketamine and $1 \mathrm{mg} / \mathrm{kg}$ medetomidine, as follows:

i) G0 females were killed 13 months after delivery.

ii) G1 animals (both males and females) were randomly selected from each treatment group and killed at: birth (B) (mean of three pups - two females and one male - per litter), 3 months of age (3M, young adulthood, mean of four pups - two males and two females - per litter) and 13 months of age (13M, late adulthood, mean of three pups - two females and one male - per litter).

In all cases, whole blood was collected by cardiac puncture and serum or plasma-EDTA was separated by centrifugation and kept at $-80^{\circ} \mathrm{C}$ until analyzed. The organs and tissues were dissected, weighed, and immediately snap frozen in liquid nitrogen, and then kept at $-80^{\circ} \mathrm{C}$ for future analyses.

\section{Quantification of blood biochemical, metabolic, and inflammatory parameters}

Serum glucose, uric acid, C-reactive protein (CRP), LDL, and HDL cholesterol were quantified using conventional methods with an Olympus AU5400 automated clinical chemistry analyzer (Beckman-Coulter, Izasa, Porto, Portugal). Homocysteine was measured by chemiluminescent immunoassay using an Architect i2000 SR automated analyzer (Abbott).

Serum folate was quantified by time-resolved fluoroimmunoassay using an AutoDelfia automated analyzer (PerkinElmer Life and Analytical Sciences, Wallac Oy, Turku, Finland).

Plasma insulin, leptin, and adiponectin were quantified by ELISA using commercially available kits according to the manufacturer's instructions (insulin and leptin: Millipore, St Charles, MO, USA; adiponectin: Invitrogen Corporation). According to the instructions, if the difference between duplicate results of a sample was over $>15 \%$ (of the coefficient of variation), the sample was repeated whenever it was possible. Sensitivities of the assays were $0.2 \mathrm{ng} / \mathrm{ml}$ (insulin), $0.04 \mathrm{ng} / \mathrm{ml}$ (leptin), and $50 \mathrm{pg} / \mathrm{ml}$ (adiponectin).

Serum interleukin 1 beta (IL1 $\beta$ ), interleukin 10 (IL10), and transforming growth factor-beta 1 (TGF 31 ) were measured by Luminex assay using the custom Milliplex Rat kits (Merck Millipore, Madrid, Spain), according to the manufacturer's protocols, by Luminex xMAP Multiplexing Technology platform.

\section{Oral glucose tolerance assessment}

Oral glucose tolerance tests (OGTT) were performed in animals fasted for $4 \mathrm{~h}$ using OneTouch Ultra Blood Glucose Meter (Lifescan Canada Ltd, Burnaby, British Columbia, Canada). Glucose was administered by gavage ( $2 \mathrm{~g}$ of glucose/kg body weight) and blood glucose was quantified at $0,15,30,60,90$, and $120 \mathrm{~min}$, by lateral tail vein puncture.

\section{Bioelectrical impedance}

Body fat was determined by bioelectrical impedance, using a Quantum/S bioelectrical impedance analyzer (RJL Systems, Akern SRL, Florence, Italy), according to methods published previously (Smith et al. 2009).

\section{Blood pressure measurement}

For 1 week before measurement of systolic blood pressure (SBP), animals were acclimated daily to the procedure room and handling. Indirect measurement of SBP in awake-restrained rats was carried out by the non-invasive tail-cuff method, using LE 5000 (Letica, Barcelona, Spain). To make the pulsations of the tail artery detectable, rats were kept at $37^{\circ} \mathrm{C}$ for $15 \mathrm{~min}$ before the measurements. After obtaining a stable pulse (300 HR), three to five consecutive measurements of SBP were taken and the average of them was considered for the analysis.

\section{Calculations and statistics}

As experimental exposure was performed upon the mothers (G0) and not the offspring (G1), the population size $(n)$ considered for statistical analyses refers to the number of litters rather than the number of pups. Given the size of the litters obtained, the greater amount of females than males obtained in both treatment groups, and the division of animal groups by sex, treatment and age, the mean number of pups representing each litter at birth and at $13 \mathrm{M}$ is three (two females and one male).

Published by Bioscientifica Ltd 
The mean number of pups representing each litter at $3 \mathrm{M}$ is four (two females and two males).

The Lee index, an equivalent of the BMI in humans, was calculated according to the equation: Lee index $=$ body weight $^{1 / 3}(\mathrm{~g}) /$ nasal-anal length $(\mathrm{cm}) \times 1000$ (de Moura et al. 2009).

Data are expressed as means \pm s.E.M. For comparisons between two groups, the unpaired $t$-test was used. For comparisons between more than two groups, one-way ANOVA followed by the Tukey's post hoc test was used. Data concerning different ages and different treatments (two variables) were analyzed using two-way ANOVA, followed by the Bonferroni post hoc test. Differences were considered significant for $P<0.05$.

\section{Results}

\section{Gestational and morphometric data}

Gestational and morphometric data are given in Table 1. Although gestational data, such as mating efficiency, gestational age at birth, litter size, and the femaleto-male ratio, do not differ between treatment groups, morphometric measures tend to be higher in the HFA group, achieving statistical significance for maternal Lee index and female birth weight.

We found that pancreas weight at birth of wholeoffspring population was significantly higher in HFA group, when compared with controls $(0.02378 \pm 0.00167$ versus $0.03440 \pm 0.00064 \mathrm{~g}$ in the $\mathrm{C}$ and HFA groups respectively; $n=3$ ). This difference was not statistically significant when pancreas weight was stratified by sex. We found no differences in the weight of pup liver, heart, or brain at birth between treatment groups (data not shown).
In older animals ( 3 and 13 months of age), HFA supplementation was associated with an increased heart weight in female offspring (at 3 months of age: $0.869 \pm$ $0.043 \mathrm{~g}$ versus $0.784 \pm 0.042 \mathrm{~g}$ in the HFA and $\mathrm{C}$ groups respectively; and at 13 months of age: $1.064 \pm 0.026 \mathrm{~g}$ versus $0.994 \pm 0.012 \mathrm{~g}$ in the HFA and C groups respectively; $n=4-5$ ), but not in male offspring (Supplementary Table 2, see section on supplementary data given at the end of this article). No differences between HFA and C groups at 3 or 13 months of age were found in the weight of pancreas, liver, brain, mesenteric, or gonadal adipose tissue (Supplementary Table 2).

\section{HFA mothers have increased weight gain and reveal hyperphagia and hyperdypsia after the end of HFA exposure}

Although maternal weight was not significantly different in the $\mathrm{C}$ and HFA groups at the time of delivery (Fig. 2 and Table 1), HFA mothers displayed increased weight gain from 22 weeks (154 days) after the end of the treatment period (weaning) until the end of the study (450 days).

In addition, HFA mothers ingested more food (Fig. 2B and C) and water (Fig. 2D and E) particularly after FA supplementation had been stopped, i.e. at weaning.

Interestingly, at the end of the study, HFA mothers had less gonadal (non-visceral) adipose tissue masses $(18.40 \pm 0.54 \mathrm{~g}$ versus $20.82 \pm 0.83 \mathrm{~g}$ in HFA versus $\mathrm{C}$ mothers respectively; $n=3-5$ ) with a concomitant tendency (although not statistically significant) for greater mesenteric (visceral) adipose tissue masses when compared with control mothers $(18.93 \pm 2.75 \mathrm{~g}$ versus $16.43 \pm 1.385 \mathrm{~g}$ in HFA versus $\mathrm{C}$ mothers, respectively; $n=3-5$; Supplementary Table 3 , see section on

Table 1 Gestational and morphometric data. Values represent means \pm s.E.M. $(n)$

\begin{tabular}{l}
\hline \\
\hline G0 \\
Mating efficiency (days) \\
Gestational age at birth (days) \\
Maternal body weight $(\mathrm{g})^{\mathrm{b}}$ \\
Maternal Lee index $\left(\mathrm{g}^{1 / 3} / \mathrm{cm}\right)^{\mathrm{c}}$ \\
G1 \\
Litter size ( $\mathrm{n}$ pups) \\
Female-to-male ratio \\
Birth weight $(\mathrm{g})$ \\
Female \\
Male \\
Placental weight $(\mathrm{g})$
\end{tabular}

\begin{tabular}{c}
\hline $\mathbf{C}$ \\
$3.4 \pm 1.0(5)$ \\
$21.0 \pm 0.3(5)$ \\
$390.6 \pm 9.0(5)$ \\
$332.1 \pm 4.5(5)$ \\
$15.8 \pm 0.7(5)$ \\
$1.8 \pm 0.5(4)$ \\
$5.326 \pm 0.451(5)$ \\
$5.717 \pm 0.113(4)$ \\
$5.802 \pm 0.260(4)$ \\
$0.5553 \pm 0.0897(3)$
\end{tabular}

\begin{tabular}{c}
\hline HFA \\
\hline \\
$2.0 \pm 0.4(5)$ \\
$21.4 \pm 0.2(5)$ \\
$413.8 \pm 11.9(5)$ \\
$346.0 \pm 3.5(5)$ \\
$13.4 \pm 1.6(5)$ \\
$3.3 \pm 1.5(3)$ \\
$6.491 \pm 0.417(4)$ \\
$6.659 \pm 0.3515(2)$ \\
$7.078 \pm 0.628(2)$ \\
$0.7438 \pm 0.0596(4)$ \\
\hline
\end{tabular}

\begin{tabular}{c}
\hline $\boldsymbol{P}$ \\
\hline 0.2476 \\
0.3466 \\
0.1572 \\
0.0393 \\
0.2033 \\
0.2909 \\
0.1066 \\
0.0263 \\
0.0803 \\
0.1268 \\
\hline
\end{tabular}

${ }^{a}$ Corresponds to the number of days from mating to conception determined by vaginal plug detection.

${ }^{\mathrm{b}}$ Body weight 3-4 days before delivery.

cCalculation based on maternal body weight 3 days before delivery.

http://joe.endocrinology-journals.org DOI: 10.1530/JOE-14-0448
() 2015 Society for Endocrinology Printed in Great Britain
Published by Bioscientifica Ltd. 


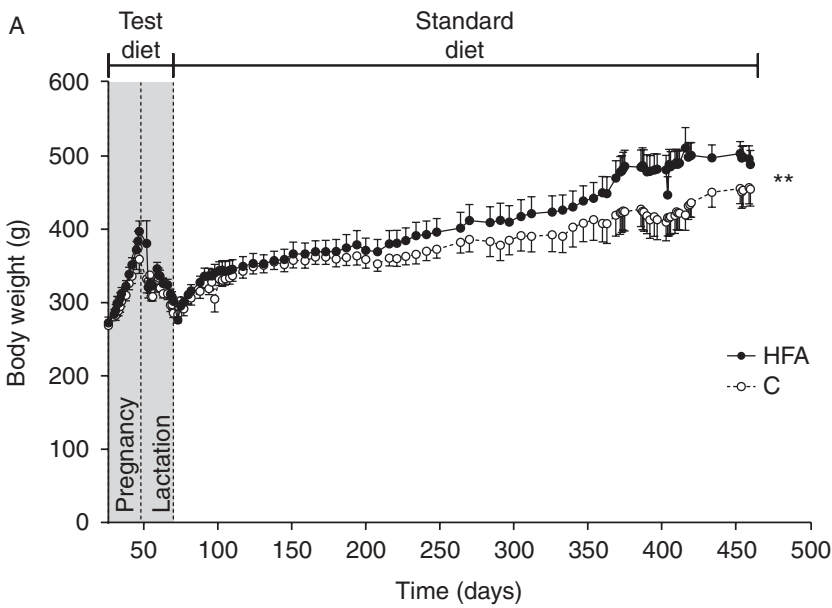

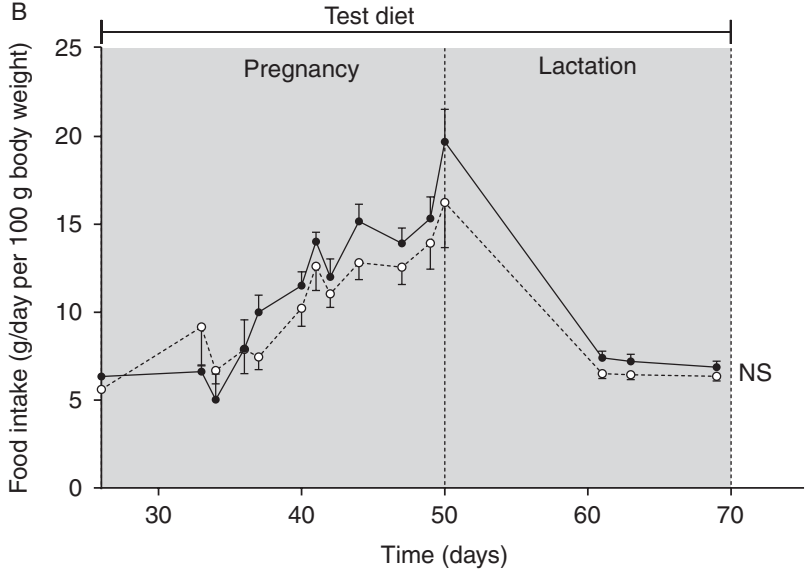

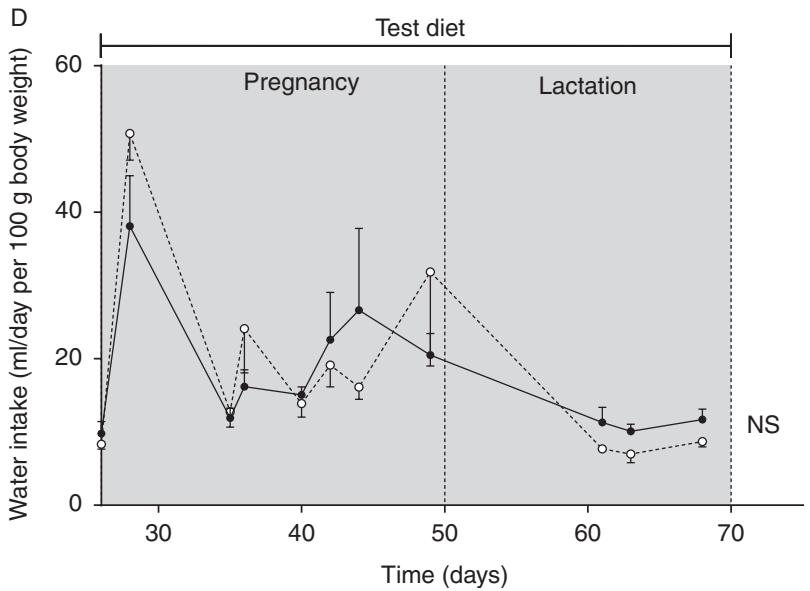

Figure 2

G0 (maternal) body weight and feeding. Treatment diets (C or HFA) were given from beginning of mating till the end of lactation (grey background) when they were replaced with a standard rat diet in both groups. G0 body weight ( $A$ ) and food ( $B$ and $C$ ) and water ( $D$ and $E$ ) intake, adjusted for body weight, were measured daily from the beginning of the study till weaning and every 5-7 days thereafter. The arithmetical means + S.E.M. (HFA, $n=5)$ and the arithmetical means-S.E.M. $(C, n=5)$ are shown.
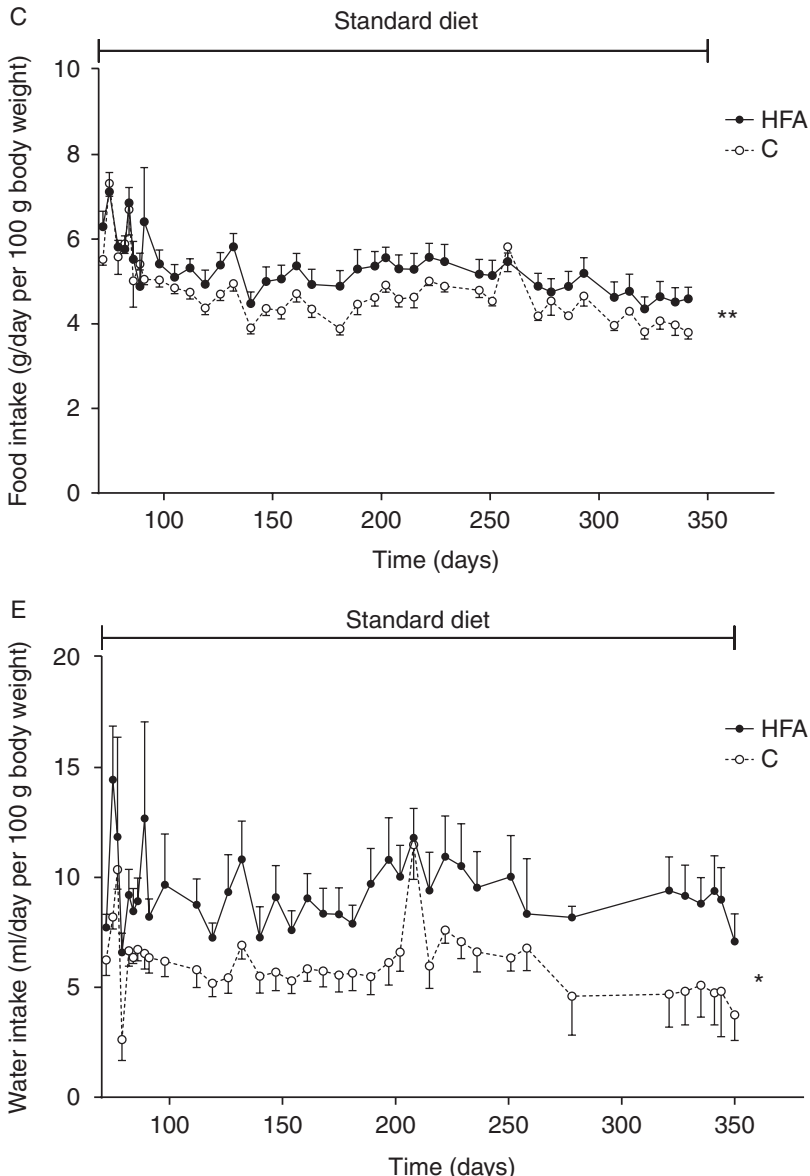

Two-way ANOVA indicated a significant effect of HFA upon G0 body weight $(P<0.0001)$ and food $(P<0.0001)$ and water $(P<0.0001)$ intake after weaning. Age was also found to affect $\mathrm{G0}$ body weight $(P<0.0001)$ and food $(P<0.0001)$ and water $(P=0.0003)$ intake. There was no interaction between the effects of HFA and age. ${ }^{*} P<0.0001 ;{ }^{*} P<0.05 ; \mathrm{NS}$, not statistically significant.

Published by Bioscientifica Ltd. 
supplementary data given at the end of this article). Also, maternal fat mass at the end of the study was not significantly different between treatment groups (Supplementary Table 3).

\section{HFA female offspring have increased weight gain and disturbed feeding behavior}

Female offspring of HFA mothers not only revealed increased birth weight (Table 1), but also presented increased weight gain, evident from early adulthood and accentuating with aging (Fig. 3A). There were no
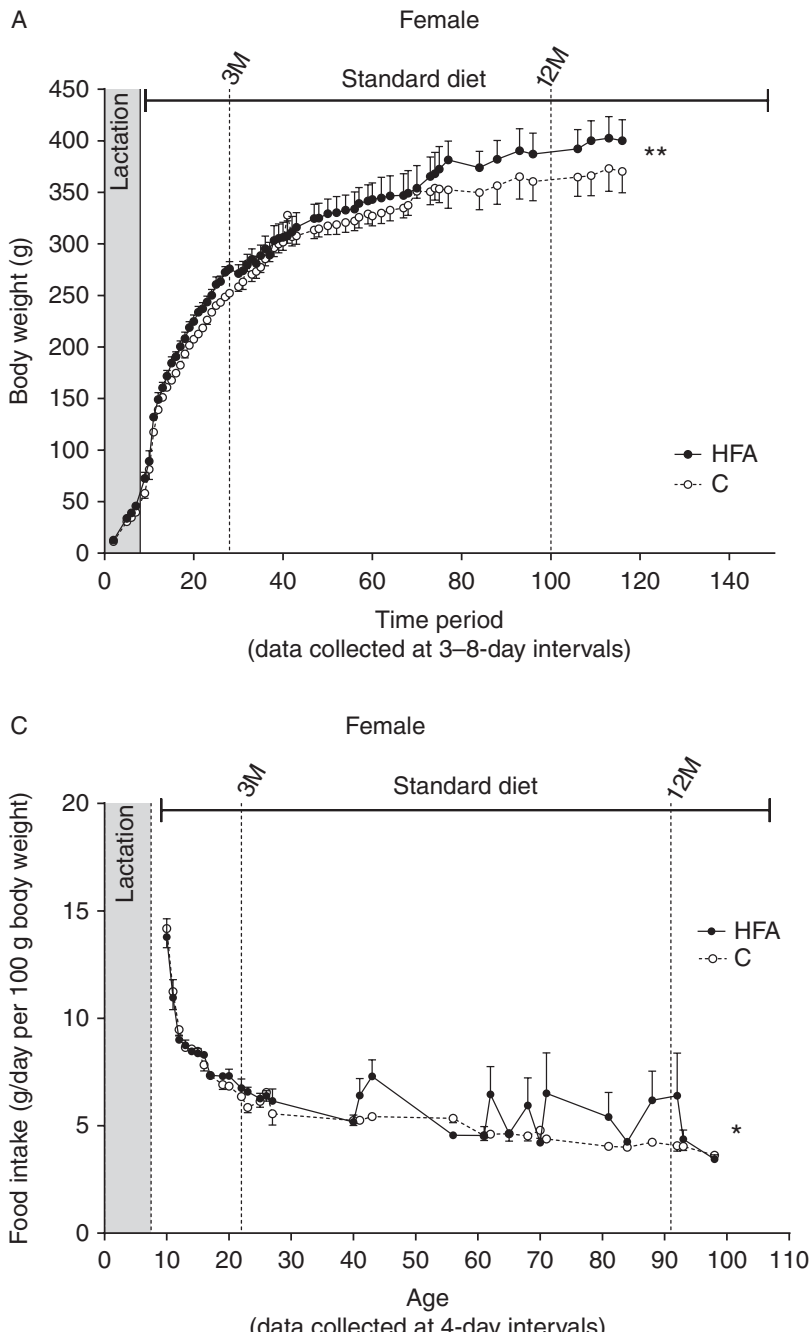

(data collected at 4-day intervals)

Figure 3

G1 (offspring) body weight and feeding. Treatment diets (C or HFA) were given to $\mathrm{GO}$ from beginning of mating till the end of lactation (grey background) when they were replaced with a standard rat diet in both groups. Body weight of $\mathrm{G} 1$ females and males ( $\mathrm{A}$ and $\mathrm{B}$, respectively) and food intake of $G 1$ females and males ( $C$ and $D$ respectively) were measured every 3 days from birth till killing. The arithmetical means +s.E.M. (HFA, $n=5)$ differences in weight gain between HFA and C groups for male offspring (Fig. 3B).

In line with these findings, HFA females developed increased food intake from 3 months after weaning onwards. Notably, this increase in food intake was not consistent over time, revealing disturbed feeding behavior in this female population (Fig. 3C). On the other hand, HFA supplementation increased food intake to a much smaller extent in male offspring (Fig. 3D), and there were no signs of disturbance in feeding behavior. There were no differences in water intake between HFA and C groups for female or male offspring (data not shown).
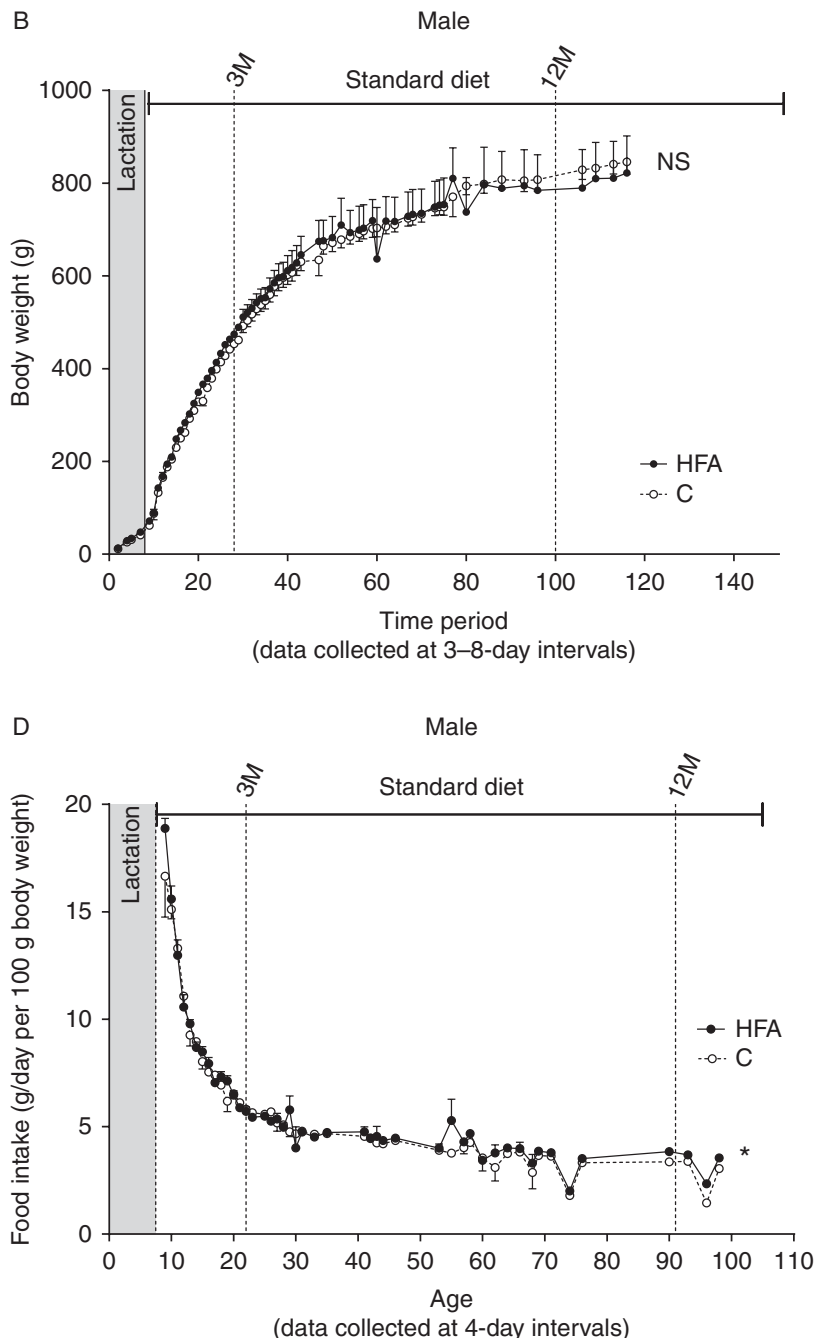

and arithmetical means-S.E.M. (C, $n=4)$ are shown. Two-way ANOVA indicated a significant effect of HFA upon body weight of $\mathrm{G} 1$ females $(P<0.0001)$, and food intake of $\mathrm{G} 1$ females $(P=0.0009)$ and $\mathrm{G} 1$ males $(P=0.0132)$. Age was found to affect all the measured parameters $(P<0.0001)$. There was no interaction between the effects of HFA and age for any of the parameters. ${ }^{*} P<0.0001 ;{ }^{\star} P<0.05$; NS, not statistically significant.

Published by Bioscientifica Ltd 
No changes were found in blood pressure and fat mass of HFA when compared with $C$ offspring

For G1 animals (whole-population, females and males) we found no differences in blood pressure at 3 or 13 months of age and in fat mass at 13 months of age between C or HFA groups (Supplementary Table 2).

\section{HFA offspring have impaired glycemic control}

Blood general biochemistry with a particular focus on glycemic control markers was assessed in G1.

At 3 months of age we found no alterations in serum homocysteine, LDL, HDL, uric acid, or CRP in offspring (whole, female, and male) populations (data not shown). Serum folate levels tended to be higher in HFA offspring, albeit the difference was not significant (39.92 \pm $2.221 \mathrm{nmol} / \mathrm{l}$ versus $35.73 \pm 1.932 \mathrm{nmol} / \mathrm{l}$ in $\mathrm{HFA}$ and $\mathrm{C}$ for the whole offspring population respectively; $n=4-5$; $40.77 \pm 1.911 \mathrm{nmol} / 1$ versus $35.45 \pm 1.930 \mathrm{nmol} / \mathrm{l}$ in HFA and $\mathrm{C}$ female offspring respectively; $n=4-5$; and $39.74 \pm$ 3.401 vs $35.02 \pm 3.556$ in HFA and $C$ male offspring respectively; $n=3-5$ ).

With respect to glycemic control, 3-month-old HFA offspring revealed increased glycemia when compared with matched controls (Fig. 4A). After stratification by sex, we observed that this difference is statistically significant only in females (Fig. 4B, and C). Moreover, this impaired glycemic control is persistent with aging, as disclosed by decreased oral glucose tolerance in both sexes at 13 months of age (Fig. 4D, E, and F).

\section{HFA induces changes in hormone and adipokine blood levels in $\mathbf{G 1}$}

Insulin and adipokines in plasma of $3 \mathrm{M}$ and $13 \mathrm{M}$ G1 animals were quantified. There were no differences in plasma insulin levels between $\mathrm{C}$ and HFA groups at $3 \mathrm{M}$. However, at 13M, HFA supplementation increased insulin levels in female (but not in male) offspring, when compared with control (Fig. 5A, B, and C).

In addition, it can be observed that aging tends to reduce insulin plasma levels, which seems to be due to a reduction in pancreas weight with aging observed in the whole population (in the $\mathrm{C}$ group: $1.985 \pm 0.148 \mathrm{~g}$ versus $1.811 \pm 0.088 \mathrm{~g}$ at 3 and 13 months of age respectively; $n=4$ and in the HFA group: $2.298 \pm 0.157$ g versus $1.769 \pm$ $0.118 \mathrm{~g}$ at 3 and 13 months of age respectively; $n=5$ ) and in female population (in $\mathrm{C}$ group: $1.726 \pm 0.166 \mathrm{~g}$ versus $1.703 \pm 0.084 \mathrm{~g}$ at 3 and 13 months of age, respectively; $n=4$ and in HFA group: $2.043 \pm 0.144 \mathrm{~g}$ versus $1.517 \pm$ $0.081 \mathrm{~g}$ at 3 and 13 months of age, respectively; $n=5$ ) in both treatment groups (Supplementary Table 2).
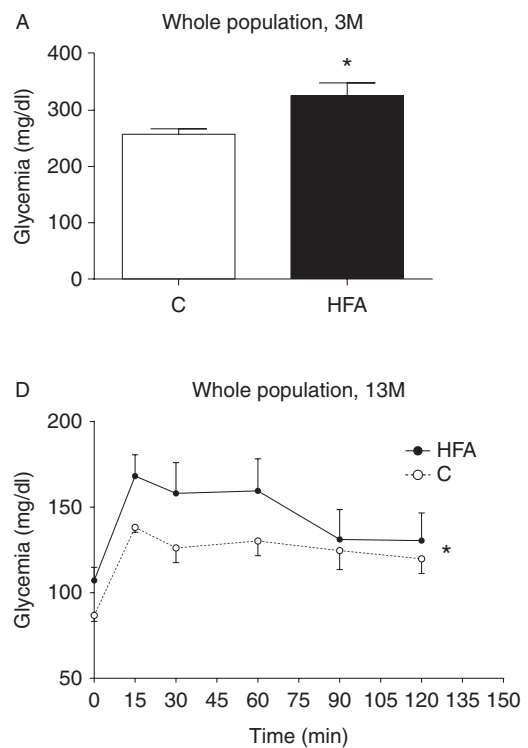
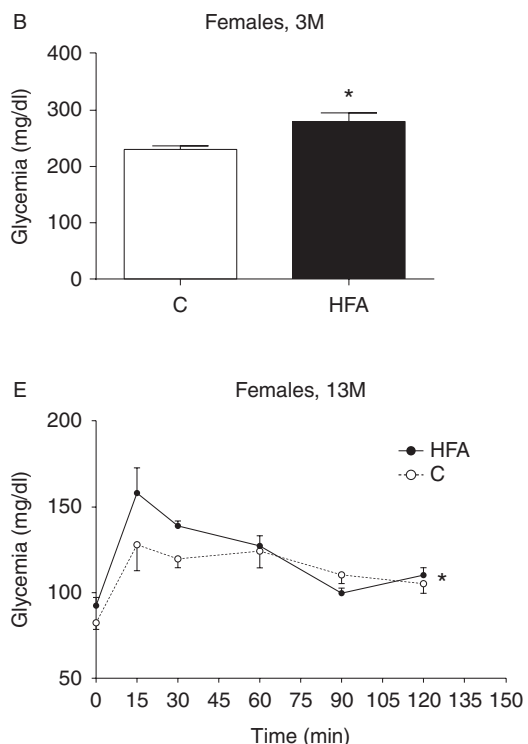
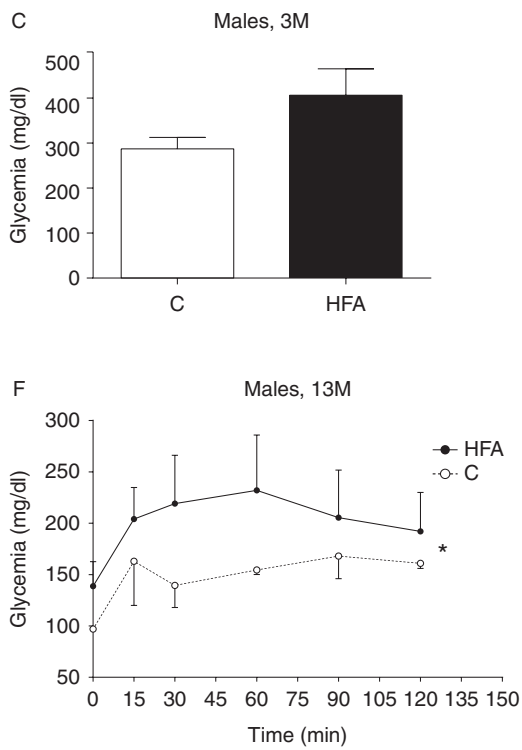

Figure 4

G1 (offspring) glycemic control. Plasma glucose was measured at 3 months of age in the whole (A), female (B), and male (C) G1 populations ( $n=4$ and 5 for C and $H F A$ respectively). At 13 months of age, glucose tolerance was assessed in the whole (D), female (E), and male (F) G1 populations ( $n=2-4$ and 3-5 for C and HFA respectively). The arithmetical means \pm s.E.M. are shown. $T$-test indicated a significant effect of HFA upon glycemia in the whole population and G1 females, at 3 months of age. Two-way ANOVA indicated a significant effect of HFA upon glycemia in oral glucose tolerance tests in the whole $(P=0.0082)$, female $(P=0.0450)$, and male $(P=0.0364) \mathrm{G} 1$ populations. No interaction was found between the effects of HFA and time for OGT. $* P<0.05$.

Published by Bioscientifica Ltd. 
A

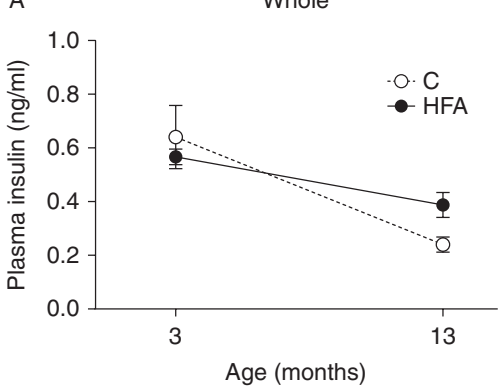

D
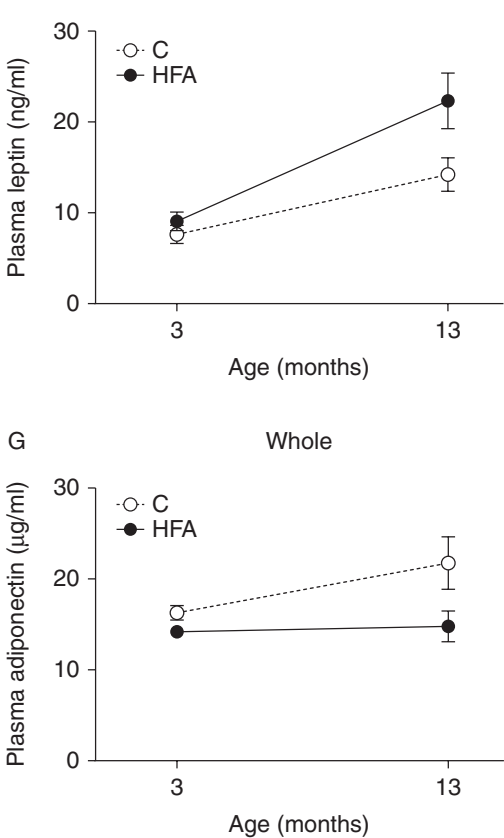

B
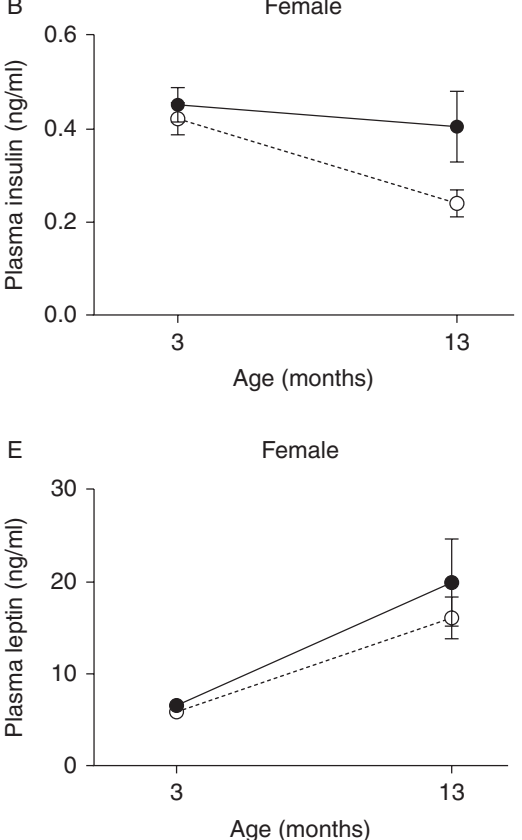

$\mathrm{H}$

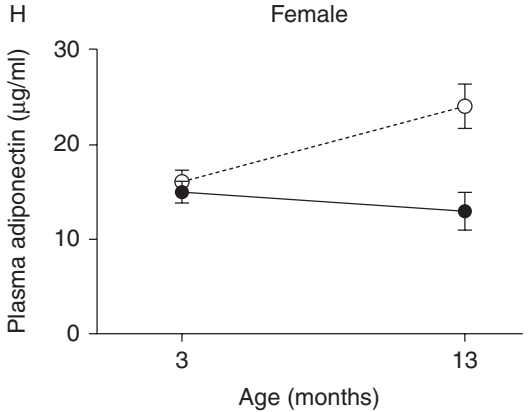

C Male

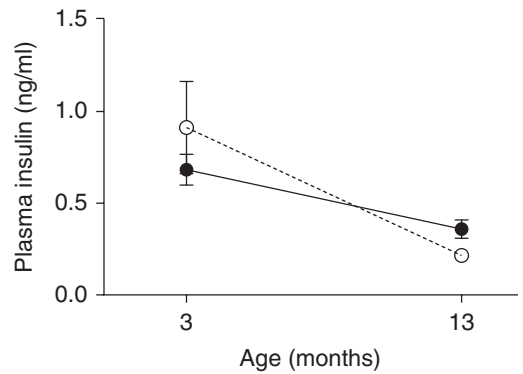

F
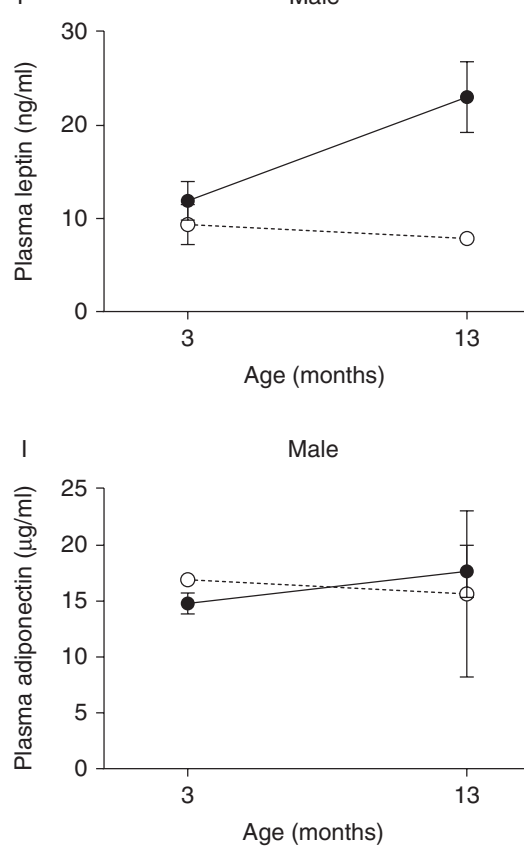

Figure 5

Plasma levels of insulin ( $A, B$, and $C)$, leptin $(D, E$, and $F)$, and adiponectin $(G, H$, and $I)$ in $G 1$ (offspring) whole ( $A, D$, and $G)$, female $(B, E$, and $H)$, and male $(C, F$, and I) populations at 3 and 13 months of age. The arithmetical means \pm S.E.M. ( $n=4-5$ and $1-5$ for 3 and 13 months of age, respectively) are shown. Two-way ANOVA indicated a significant effect of HFA upon plasma levels of insulin in female $(P=0.0489)(B)$ and a significant effect of age in whole $(P=0.0011)(A)$, female $(P=0.0251)(B)$, and male (C) $(P=0.0401) \mathrm{G} 1$ populations. Two-way ANOVA also indicated a significant effect of HFA upon leptin plasma levels in whole $(P=0.0200)(D)$ and male $(P=0.0253)$

With regard to leptin, HFA supplementation significantly accounted for increased leptinemia in the whole population at 13 months of age (Fig. 5D). When stratifying by sex, the effect is significant only for male offspring (Fig. $5 \mathrm{E}$ and $\mathrm{F}$ ).

It was also observed that the levels of leptin in the whole and female offspring populations increased with age (Fig. 5D and E).

Quantification of adiponectin also retrieved interesting results (Fig. 5G, H, and I). HFA caused a decrease in adiponenctin plasma levels both in whole (Fig. 5G) and
(F) G1 populations and a significant effect of age in whole $(P=0.0002)$ (D) and female ( $P=0.0004)$ (E) G1 populations. No interaction was found between the effects of HFA and age upon plasma leptin levels. Regarding adiponectin, two-way ANOVA indicated a significant effect of HFA upon plasma levels of adiponectin in whole $(P=0.0114)(G)$ and female $(P=0.0037)(H) G 1$ populations. In $\mathrm{G} 1$ females an interaction between the effects of HFA and age upon adiponectin plasma levels $(P=0.0124)(G)$. No significant effect of age upon adiponectin plasma levels was observed.

in female (Fig. $5 \mathrm{H}$ ) offspring populations, but not in male offspring (Fig. 5I), at 13 months of age.

Serum levels of IL1 $\beta$, IL10, and TGF $\beta 1$ were quantified in female offspring and did not show significant differences between treatment groups (data not shown).

\section{Fructose intake stimulates weight gain in HFA females}

The effect of HFA perigestational supplementation with HFA upon the offspring's susceptibility to develop metabolic dysfunction in response to a metabolic challenge was

Published by Bioscientifica Ltd 
assessed by feeding fructose to 10-month-old offspring for 3 months, until the end of the study.

The fructose-fed SD rat (FFSD) is a well characterized animal model of the MetS (Oron-Herman et al. 2008) as these animals exhibit numerous features of the MetS, including insulin resistance, hyperinsulinemia, hypertriglyceridemia, and hypertension.

While fructose ingestion did not affect the profile of weight gain in $\mathrm{C}$ female offspring (no differences in percentage weight gain between C/Fru and C/Std, Fig. 6A), it resulted in an increase in weight gain in HFA-exposed female offspring (\% weight gain is higher in HFA/Fru versus HFA/Std, Fig. 6B). C/Fru and HFA/Fru females ingested higher amounts of water, than C/Std (Fig. 7A) and HFA/Std (Fig. 7B) females, respectively, as expected, given the sweetness of fructose which confers higher palatability to the drinking water. This produced a compensatory decrease in food ingestion in both fructose-fed C and HFA females (Fig. 8A and B).

With regard to male offspring, feeding with fructose did not affect percentage weight gain in C or in HFA groups (Fig. 6C and D). Notwithstanding this, C/Fru males displayed increased water intake when compared with $\mathrm{C} / \mathrm{Std}$ males (Fig. 7C), though no differences in water intake were observed between HFA/Fru and HFA/Std males (Fig. 7D).
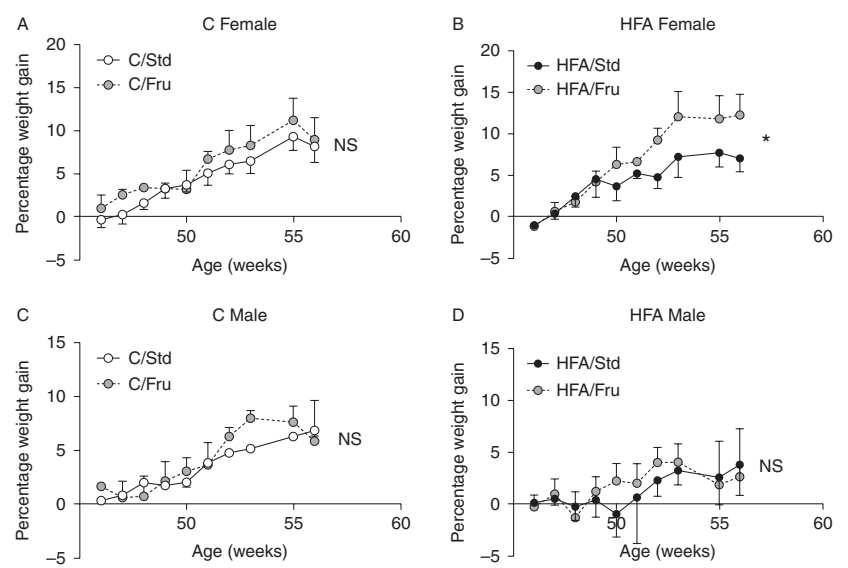

Figure 6

G1 (offspring) body weight follow-up after feeding with fructose. Each G1 group (C and HFA) was divided, at 10 months (or 46 weeks) of age, into a standard group fed the standard rat diet (C/Std and HFA/Std, $n=2-4$ and 3-5 respectively) and a high-fructose group, fed a high dose of fructose (10\% fructose in the drinking water) plus the standard rat diet (C/Fru and $\mathrm{HFA} / \mathrm{Fru}, n=3-4$ each). Body weight of $\mathrm{G} 1$ was registered once a week for $\mathrm{C}$ females (A) and males (C) and for HFA females (B) and males (D).

The arithmetical means \pm s.E.M. are shown. Two-way ANOVA indicated a significant effect of fructose feeding upon percentage weight gain of HFA females $(P=0.0193)$ ( $B$ ) and of age upon percentage weight gain $(P<0.0001)$ of $C$ females (A), HFA females $(P<0.0001)(B)$, and $C$ males $(P=0.0033)(C)$ in $\mathrm{G} 1$ populations. No interaction was found between the effects of Fru and age. NS, not statistically significant; *, $P<0.05$.
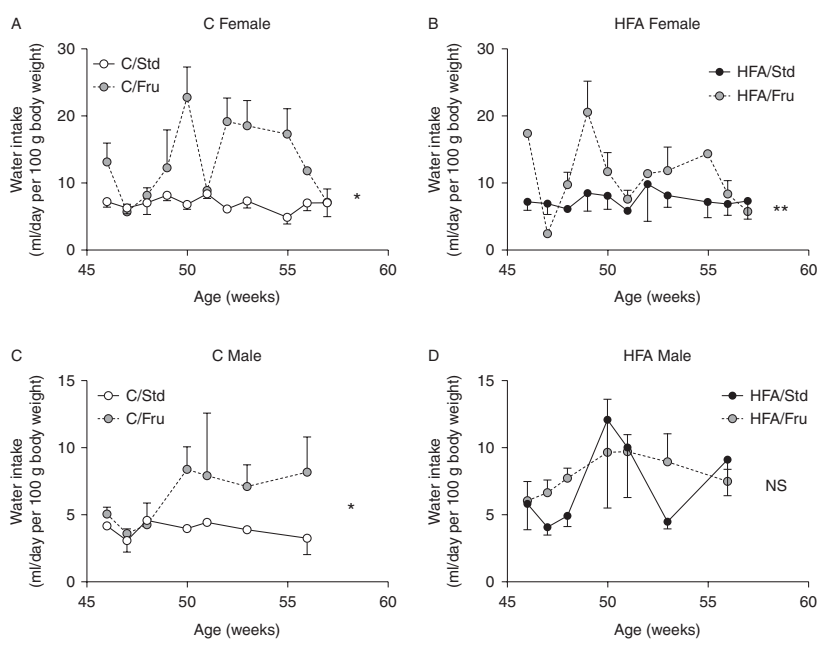

Figure 7

G1 (offspring) water intake follow-up after feeding with fructose. Each G1 group ( $\mathrm{C}$ and HFA) was divided, at 10 months (or 46 weeks) of age, into a standard group fed the standard rat diet (C/Std and HFA/Std, $n=2-4$ and $3-5$, respectively) and a high-fructose group fed a high dose of fructose ( $10 \%$ fructose in the drinking water) plus the standard rat diet (C/Fru and HFA/Fru, $n=3-4$ each). Water intake by G1 was registered once a week for females ( $A$ and $B$ ) and males ( $C$ and $D)$. The arithmetical means \pm s.E.M. are shown. Two-way ANOVA indicated a significant effect of feeding with fructose upon water intake by $C$ females $(P<0.0001, A)$, HFA females $(P<0.0001, \mathrm{~B})$, and $\mathrm{C}$ males $(P=0.0499, \mathrm{C})$ of $\mathrm{G} 1$ populations. Two-way ANOVA also indicated a significant effect of age upon water intake by, C females $(P=0.0055, \mathrm{~A})$ and by HFA females $(P=0.0466, \mathrm{~B})$ of $\mathrm{G} 1$ populations, and interaction between the effects of high-fructose feeding and age in G1 C females $(P=0.0022, A) .{ }^{*} P<0.0001 ; * P<0.05$; NS, not statistically significant.

With respect to food intake, supplying fructose in the drinking water produced a decrease in food intake in both $\mathrm{C}$ and HFA males (Fig. 8C and D). Importantly, feeding with fructose was able to increase fat mass, at 13M, in HFA females, but it did not affect the amount of fat mass in the whole population or male offspring (Fig. 9). Fructose feeding did not affect blood pressure or organ weight of pancreas, liver, heart, gonadal, or mesenteric adipose tissue, measured at the end of the study (13 months of age) (data not shown).

\section{Discussion}

In this study, we tested the hypothesis that exposure to high levels of FA during the early stages of development programs the offspring to develop metabolic dysfunction later in life. For this, we exposed SD female rats to a high dose of FA during the perigestational period, and we closely monitored the metabolic phenotype of the offspring from birth to 13 months of age.

Published by Bioscientifica Ltd 

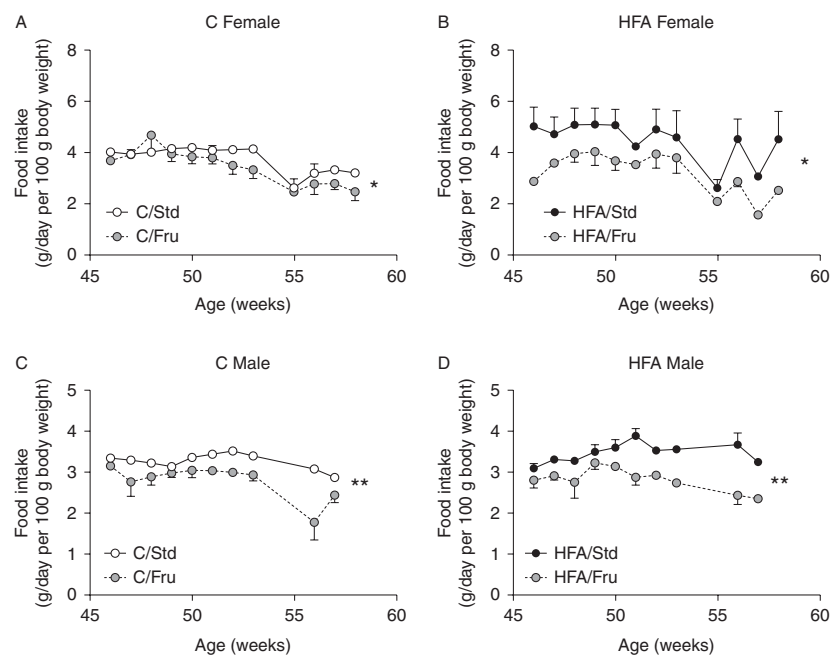

Figure 8

Food intake of G1 (offspring) follow-up after feeding with fructose. Each G1 group (C and HFA) was divided, at 10 months (or 46 weeks) of age, into a standard group fed the standard rat diet (C/Std and HFA/Std, $n=2-4$ and $3-5$, respectively) and a high-fructose group, fed a high dose of fructose (10\% fructose in the drinking water) plus the standard rat diet (C/Fru and HFA/Fru, $n=3-4$ each). Food intake by G1 animals was registered once a week for females ( $A$ and $B$ ) and males ( $C$ and $D$ ). The arithmetical means \pm S.E.M. are shown. Two-way ANOVA indicated a significant effect of feeding with fructose upon food intake by $C$ females $(P=0.0139, A)$, HFA females $(P=0.0003, \mathrm{~B}), \mathrm{C}$ males $(P<0.0001, \mathrm{C})$, and HFA males $(P<0.0001, \mathrm{D})$ of $\mathrm{G} 1$ populations. Two-way ANOVA also indicated a significant effect of age upon food intake by $C$ females $(P<0.0001, A)$ and by $C$ males $(P=0.0081, C)$ of $\mathrm{G} 1$ populations. No interactions were found between the effects of high-fructose feeding and age. ${ }^{*} P<0.0001 ;{ }^{*} P<0.05$.

The main findings of this study are summarized in Table 2. We can conclude that exposure to HFA during the perigestational period causes deterioration of the offspring's metabolic profile, particularly in females, and that the resulting overt metabolic dysfunction, revealed by increased weight gain, disturbed feeding behavior, glucose intolerance, increased insulin and decreased adiponectin plasma levels (in females), and increased leptin plasma levels (in males) develops in mid-to-late adulthood. Indeed, these alterations were observed many months after the treatment diets (C or HFA) had been replaced by the standard rat chow in both treatment groups, upon weaning, strikingly corroborating a longterm programing effect unrelated to the organoleptic features of the treatment diets. Importantly, at 3 months of age, folate levels in the serum of offspring were not significantly different between treatment groups.

Perigestational exposure to HFA was herein found to program particularly female offspring to ingest increased amounts of standard rat chow in an erratic, disturbed feeding behavior, which is likely to underlie the observed increase in weight gain. This finding strongly corroborates the idea of fetal programing of feeding behavior. Several studies have revealed evidence that maternal nutrient restriction affects offspring feeding behavior, measured either by macronutrient preference or by total energy intake (Vickers et al. 2000, Bellinger et al. 2004, Bellinger \& Langley-Evans 2005, Porto et al. 2009, Engeham et al. 2010). Curiously, many of those studies have also described a female-specific programing effect, either in fatty food preference (Bellinger \& Langley-Evans 2005), in failure to

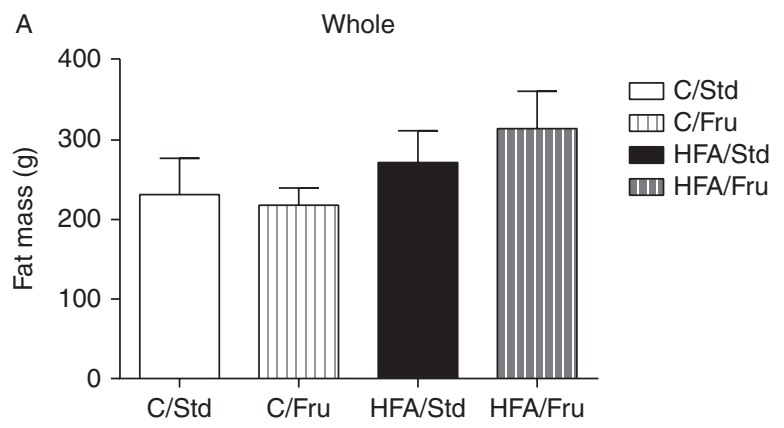

B Female
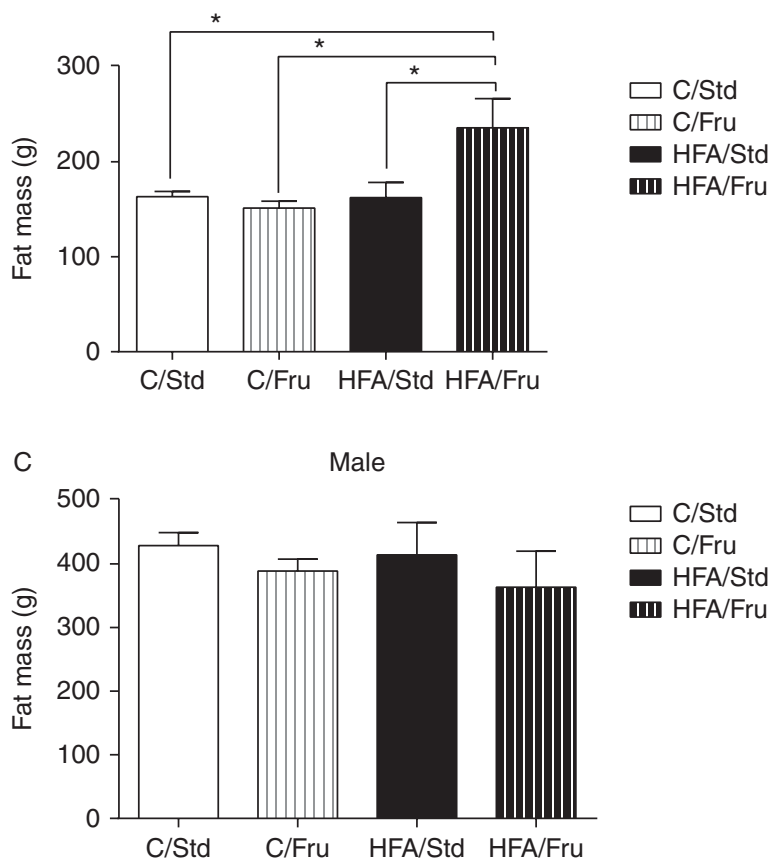

Figure 9

Fat mass of $\mathrm{G} 1$ (offspring) whole (A), female (B), and male (C) populations at 13 months of age. Each G1 group ( $C$ and HFA) was divided, at 10 months (or 46 weeks) of age, into a standard group fed the standard rat diet (C/Std and HFA/Std, $n=2-4$ and 3-5, respectively) and a high fructose group, fed a high dose of fructose ( $10 \%$ fructose in the drinking water) plus the standard rat $\operatorname{diet}$ (C/Fru and HFA/Fru, $n=3-4$ and 3-5 respectively). Fat mass of G1 animals was quantified by bioelectric impedance before the animals were killed at 13 months of age. The arithmetical means \pm s.E.M. are shown. ${ }^{*} P<0.05$.

Published by Bioscientifica Ltd. 
Table 2 Summary of the main findings of the study

\begin{tabular}{|c|c|c|c|c|}
\hline \multirow[t]{2}{*}{ HFA vs C } & \multicolumn{2}{|c|}{ G1 female } & \multicolumn{2}{|c|}{ G1 male } \\
\hline & $3 M$ & $13 \mathrm{M}$ & $3 \mathrm{M}$ & $13 \mathrm{M}$ \\
\hline Weight gain & $\uparrow$ & $\uparrow \uparrow$ & $\leftrightarrow$ & $\leftrightarrow$ \\
\hline Food intake & $\uparrow$ & $\uparrow \uparrow$ & $\leftrightarrow$ & $\uparrow$ \\
\hline Heart weight & $\uparrow$ & $\uparrow$ & $\leftrightarrow$ & $\leftrightarrow$ \\
\hline Glycemic control & $\uparrow$ (Gly) & $\downarrow(\mathrm{OGT})$ & $\leftrightarrow$ & $\downarrow(\mathrm{OGT})$ \\
\hline Insulin & $\leftrightarrow$ & $\uparrow$ & $\leftrightarrow$ & $\leftrightarrow$ \\
\hline Leptin & $\leftrightarrow$ & $\leftrightarrow$ & $\leftrightarrow$ & $\uparrow$ \\
\hline Adiponectin & $\leftrightarrow$ & $\downarrow$ & $\leftrightarrow$ & $\leftrightarrow$ \\
\hline
\end{tabular}

$\uparrow$, increase; $\downarrow$, decrease; $\leftrightarrow$, no change detected; 3M, 3 months of age; $13 \mathrm{M}, 13$ month of age; Gly, glycemia; OGT, oral glucose tolerance.

adjust food intake to maintain constant energy intake (Bellinger et al. 2004), or in failure to respond to a hypophagia-inducing stimulus (Porto et al. 2009).

This study, however, is the first, to out knowledge, to obtain evidence that excess maternal micronutrient intake has an effect on feeding behavior of female progeny.

We observed that still in female offspring of HFA dams, high birth weight and hyperglycemia at 3 months of age appear as early markers of later-in-life overt metabolic dysfunction. Also, the increased pancreas weight observed at birth in offspring of HFA-exposed dams, indicative of pancreas hypertrophy or hyperplasia, may be associated with such complications. Indeed it is known that maternal diabetes, when mild, induces hypertrophy of the endocrine pancreas and hyperplasia of the B-cells in rat fetuses (Van Assche et al. 2001) and, when severe, it induces increased mass of the endocrine pancreas in adulthood (Aerts et al. 1997, Van Assche et al. 2001), in both cases associated with a deregulation of metabolic control in adulthood (Van Assche et al. 2001).

The decrease in glycemic control observed in female progeny of HFA mothers may directly result from some degree of insulin resistance herein manifested as high insulin levels in female offspring of HFA-exposed dams compared with controls. In addition, considering that adiponectin improves insulin sensitivity (Gulcelik et al. 2009, Groeneveld et al. 2012) by promoting glucose utilization (Yamauchi et al. 2002), it is likely that the observed decrease in adiponectin levels may also be involved in the impairment of glycemic control as also suggested elsewhere (Liao et al. 2005). These observations are in perfect agreement with those of Yajnik et al. (2008) who have previously shown that high concentrations of folate in maternal erythrocytes were associated with insulin resistance in the offspring.

Another interesting finding relates to the observed increase in heart weight, indicative of cardiac hypertrophy, in at 3 and 13 months of age in female offspring of dams exposed to HFA. As cardiac hypertrophy is an important feature of diabetic cardiomyopathy (DCM) (Nunes et al. 2013), we speculate that perigestational exposure to HFA may program female progeny to develop DCM, increasing the risk of heart failure (Boudina \& Abel 2010, Nunes et al. 2013). Strikingly, hyperglycemia (Murarka \& Movahed 2010), hyperinsulinemia (Boudina \& Abel 2010, Murarka \& Movahed 2010), and adiponectin deficiency (Guo et al. 2013), all manifested in HFA female offspring, have been suggested to contribute to cardiac hypertrophy (Guo et al. 2013).

Feeding with high levels of fructose was applied to the offspring, at 10 months of age, as a means of assessing the effect of exposure to HFA on their susceptibility to developing metabolic dysfunction in response to a metabolic insult. Female progeny of HFA mothers, but not those of control mothers, failed to buffer body weight and fat mass gain after feeding with fructose, although both seemed to compensate caloric intake, provided by fructose, by consuming lower amounts of food. Thus, it is likely that perigestational exposure to HFA renders female progeny more susceptible to developing metabolic unbalance upon a metabolic insult. This was not the case with C or HFA male offspring that were able to avoid body weight and fat mass gain after feeding with fructose.

The results of a study by Huang et al. (2014) strongly corroborate our findings by indicating that the administration of HFA (in the same dose used in this study) to pregnant mice worsens the metabolic response to highfat-diet stimulus in adult offspring.

Our results indicate that there is a sex-specific response to perigestational HFA. Indeed, in this study, male offspring seem to be metabolically more resistant to HFA exposure, as they show lesser and later metabolic alterations when compared with female offspring of dams exposed to HFA (Table 2). Also male progeny of dams exposed to HFA only slightly increased the intake of food, to a much lower degree than that observed in females, which was not enough to induce an increase in weight gain, as observed for female progeny of dams exposed to HFA. While the observed hyperleptinemia in male offspring of dams exposed to HFA may represent some degree of leptin resistance, and may eventually predict an increased risk of diabetes (Schmidt et al. 2006), it may also exert some anorexigenic effect (Shan $\&$ Yeo 2011) and thus protect male offspring from overt hyperphagia and from concomitant excessive weight gain, upon early-life HFA exposure.

Sex-specific responses to developmental programing have been identified in a large number of studies (see Aiken \& Ozanne (2013) for a comprehensive review).

Published by Bioscientifica Ltd. 
While it is not straightforward to conclude which sex is more sensitive to metabolic dysfunction programing, it is apparent that the type and timing of the exposure to the programer and also the animal strain will affect the outcome (Aiken \& Ozanne 2013).

In agreement with the sex dimorphism in metabolic programing indicated by the results of this study, Ravelli et al. (1999) have reported that exposure to the Dutch famine during early gestation resulted in worse obesity anthropometric measures in women but not in men at 50 years of age. On the other hand, it has been observed that male offspring of rat dams subjected to methyl-deficient diets during the periconceptional period were programed for impaired glycemic control (Maloney et al. 2011) or for a worse metabolic profile (Sinclair et al. 2007) to a greater extent than female offspring.

Although sex hormones must be considered as plausible players in sexual dimorphism, particularly in adult organisms, they may not act alone in a sex-specific response to fetal programing. This is particularly relevant when sex-specific changes are observed at early stages of development, such as the sex-specific HFA-induced increase in body weight herein detected at birth. Indeed, it is well known that there are sex-specific patterns of methylation/demethylation which arise during development which may underlie these sex-specific responses to phenotype programers, such as methyl deficient or excessive diets (Vige et al. 2008).

From the maternal follow-up, we could conclude that, in addition to the programing of metabolic dysfunction in the offspring, perigestational supplementation with HFA also causes a deterioration in the maternal (G0) longterm metabolic phenotype, as it induces an increase in maternal Lee index before delivery and programs the mothers for increased weight gain, hyperphagia, and hyperdypsia.

As a whole, we can conclude that exposure to high doses of during the perigestational period fuels later-in-life metabolic dysfunction not only in the mothers but also in their offspring, with the more marked effect on females presenting as a particular concern. Indeed, by programing female offspring, which will be dams in the future, to develop metabolic dysfunction, FA oversupplementation may strongly contribute to a snow-ball effect of an exponential increase in the prevalence of metabolic dysfunction and associated diseases such as obesity and diabetes.

Epigenetic changes in all probability may underlie the phenotypic effects of exposure to HFA during the perigestational period demonstrated in this study. Indeed, periconceptional use of FA by women has been associated with increased methylation of IGF2 in very young offspring (Steegers-Theunissen et al. 2009). In addition, very recently, maternal feeding with high levels of FA during pregnancy has been demonstrated to alter methylation status in the offspring of mice, particularly in white adipose tissue (Huang et al. 2014) and in the brain, the latter with a sex dimorphism response (Barua et al. 2014).

Many questions still warrant future research efforts. It would be desirable to determine the critical temporal windows during development, and the critical dose of FA that induces the observed programing effects. The dose used in this study ( $40 \mathrm{mg} \mathrm{FA} / \mathrm{kg}$ of diet) represents 20 times the recommended dose of FA for pregnancy in the rat. In the case of human beings, a maximum dose of $4 \mathrm{mg} F \mathrm{~F} /$ day is recommended for prevention of NTD recurrence, which corresponds to 20 times the dose initially recommended for low-risk pregnant women $(0.2 \mathrm{mg} /$ day) (de Bree et al. 1997), and ten times the current WHO recommended dose $(0.4 \mathrm{mg} /$ day). Moreover, in some countries only pills with $5 \mathrm{mg}$ of FA (or more) are available for daily intake, corresponding to 12.5 times the WHO recommended dose (and in addition, some women take multivitamin pills containing also FA and are exposed to a diversity of FA-enriched foodstuffs). So, considering that increased amounts of folates are consumed during pregnancy, not only through intake of folate-fortified foods, but also by clinical administration of FA and/or multivitamin pills, the identification of a safe upper dose is indeed urgent.

Our results, together with previous results from others (Sinclair et al. 2007, Engeham et al. 2010, Maloney et al. 2011), strongly indicate that the effect of FA supplementation during early stages of development on health programing may conform to a U-shaped curve, and thus they may play a fundamental part in the recasting of current public health policies concerning fortification of food with FA and clinical recommendations.

\section{Supplementary data}

This is linked to the online version of the paper at http://dx.doi.org/10.1530/ JOE-14-0448.

\section{Declaration of interest}

The authors declare that there is no conflict of interest that could be perceived as prejudicing the impartiality of the research reported.

\section{Funding}

This work was supported by Fundação para a Ciência e Tecnologia (FCT) the Programa Operacional Temático Factores de Competitividade (COMPETE),

Published by Bioscientifica Ltd. 
Quadro de Referência Estratégico Nacional (QREN), and the Fundo Europeu De Desenvolvimento Regional (FEDER) (PEst-OE/SAU/UI0038/2014; PTDC/SAU-OSM/102239/2008; SFRH/BPD/40170/2007).

\section{Acknowledgements}

The authors acknowledge Ana Faria, Cláudia Marques, Diana Teixeira, Diogo Pestana, Sónia Norberto, and Liliana Leite for important technical support; Laura Vilarinho and the Centre for Medical Genetics Dr Jacinto Magalhães for folate quantifications; and Prof. Isabel Azevedo for the critical review of this manuscript.

\section{References}

Achon M, Alonso-Aperte E, Reyes L, Ubeda N \& Varela-Moreiras G 2000 High-dose folic acid supplementation in rats: effects on gestation and the methionine cycle. British Journal of Nutrition 83 177-183. (doi:10.1017/S0007114500000222)

Aerts L, Vercruysse L \& Van Assche FA 1997 The endocrine pancreas in virgin and pregnant offspring of diabetic pregnant rats. Diabetes Research and Clinical Practice 38 9-19. (doi:10.1016/S0168-8227(97) 00080-6)

Aiken CE \& Ozanne SE 2013 Sex differences in developmental programming models. Reproduction 145 R1-13. (doi:10.1530/ REP-11-0489)

Bailey RL, Dodd KW, Gahche JJ, Dwyer JT, McDowell MA, Yetley EA, Sempos CA, Burt VL, Radimer KL \& Picciano MF 2010 Total folate and folic acid intake from foods and dietary supplements in the United States: 2003-2006. American Journal of Clinical Nutrition 91 231-237. (doi:10.3945/ajcn.2009.28427)

Barua S, Kuizon S, Chadman KK, Flory MJ, Brown WT \& Junaid MA 2014 Single-base resolution of mouse offspring brain methylome reveals epigenome modifications caused by gestational folic acid. Epigenetics \& Chromatin 7 3. (doi:10.1186/1756-8935-7-3)

Bellinger L \& Langley-Evans SC 2005 Fetal programming of appetite by exposure to a maternal low-protein diet in the rat. Clinical Science 109 413-420. (doi:10.1042/CS20050127)

Bellinger L, Lilley C \& Langley-Evans SC 2004 Prenatal exposure to a maternal low-protein diet programmes a preference for high-fat foods in the young adult rat. British Journal of Nutrition 92 513-520. (doi:10.1079/BJN20041224)

Boudina S \& Abel ED 2010 Diabetic cardiomyopathy, causes and effects. Reviews in Endocrine \& Metabolic Disorders 11 31-39. (doi:10.1007/ s11154-010-9131-7)

de Bree A, van Dusseldorp M, Brouwer IA, van het Hof KH \& SteegersTheunissen RP 1997 Folate intake in Europe: recommended, actual and desired intake. European Journal of Clinical Nutrition 51 643-660. (doi:10.1038/sj.ejcn.1600467)

Brown RD, Langshaw MR, Uhr EJ, Gibson JN \& Joshua DE 2011 The impact of mandatory fortification of flour with folic acid on the blood folate levels of an Australian population. Medical Journal of Australia 194 65-67.

Burdge GC \& Lillycrop KA 2010 Nutrition, epigenetics, and developmental plasticity: implications for understanding human disease. Annual Review of Nutrition 30 315-339. (doi:10.1146/annurev.nutr.012809. 104751)

Burdge GC \& Lillycrop KA 2012 Folic acid supplementation in pregnancy: are there devils in the detail? British Journal of Nutrition 108 1924-1930. (doi:10.1017/S0007114512003765)

Castro K, Klein LD, Baronio D, Gottfried C, Riesgo R \& Perry IS 2014 Folic acid and autism: what do we know? Nutritional Neuroscience (In Press). (doi:10.1179/1476830514Y.0000000142)
EFSA 2009 ESCO report prepared by the EFSA Scientific Cooperation Working Group on Analysis of Risks and Benefits of Fortification of Food with Folic Acid. pp. 1-115. Parma: EFSA.

Engeham SF, Haase A \& Langley-Evans SC 2010 Supplementation of a maternal low-protein diet in rat pregnancy with folic acid ameliorates programming effects upon feeding behaviour in the absence of disturbances to the methionine-homocysteine cycle. British Journal of Nutrition 103 996-1007. (doi:10.1017/S0007114509992662)

Gomez MF, Field CJ, Olstad DL, Loehr S, Ramage S \& McCargar LJ 2013 Use of micronutrient supplements among pregnant women in Alberta: results from the Alberta Pregnancy Outcomes and Nutrition (APrON) cohort. Maternal \& Child Nutrition (In Press). (doi:10.1111/mcn.12038)

Groeneveld MP, Huang-Doran I \& Semple RK 2012 Adiponectin and leptin in human severe insulin resistance - diagnostic utility and biological insights. Biochimie 94 2172-2179. (doi:10.1016/j.biochi.2012.01.021)

Gulcelik NE, Usman A \& Gurlek A 2009 Role of adipocytokines in predicting the development of diabetes and its late complications. Endocrine 36 397-403. (doi:10.1007/s12020-009-9234-7)

Guo R, Zhang Y, Turdi S \& Ren J 2013 Adiponectin knockout accentuates high fat diet-induced obesity and cardiac dysfunction: role of autophagy. Biochimica et Biophysica Acta 1832 1136-1148. (doi:10.1016/j.bbadis.2013.03.013)

Honein MA, Paulozzi LJ, Mathews TJ, Erickson JD \& Wong LY 2001 Impact of folic acid fortification of the US food supply on the occurrence of neural tube defects. Journal of the American Medical Association 285 2981-2986. (doi:10.1001/jama.285.23.2981)

Hoyo C, Murtha A, Schildkraut J, Forman M, Calingaert B, Demark-Wahnefried W, Kurtzberg J, Jirtle R \& Murphy S 2011 Folic acid supplementation before and during pregnancy in the Newborn Epigenetics STudy (NEST). BMC Public Health 11 46. (doi:10.1186/ 1471-2458-11-46)

Huang Y, He Y, Sun X, Li Y \& Sun C 2014 Maternal high folic acid supplement promotes glucose intolerance and insulin resistance in male mouse offspring fed a high-fat diet. International Journal of Molecular Sciences 15 6298-6313. (doi:10.3390/ijms15046298)

Liao Y, Takashima S, Maeda N, Ouchi N, Komamura K, Shimomura I, Hori M, Matsuzawa Y, Funahashi T \& Kitakaze M 2005 Exacerbation of heart failure in adiponectin-deficient mice due to impaired regulation of AMPK and glucose metabolism. Cardiovascular Research 67 705-713. (doi:10.1016/j.cardiores.2005.04.018)

Lucock M 2000 Folic acid: nutritional biochemistry, molecular biology, and role in disease processes. Molecular Genetics and Metabolism 71 121-138. (doi:10.1006/mgme.2000.3027)

Ly A, Lee H, Chen J, Sie KK, Renlund R, Medline A, Sohn KJ, Croxford R, Thompson LU \& Kim YI 2011 Effect of maternal and postweaning folic acid supplementation on mammary tumor risk in the offspring. Cancer Research 71 988-997. (doi:10.1158/0008-5472.CAN-10-2379)

Maloney CA, Hay SM, Young LE, Sinclair KD \& Rees WD 2011 A methyldeficient diet fed to rat dams during the peri-conception period programs glucose homeostasis in adult male but not female offspring. Journal of Nutrition 141 95-100. (doi:10.3945/jn.109.119453)

de Moura RF, Ribeiro C, de Oliveira JA, Stevanato E \& de Mello MA 2009 Metabolic syndrome signs in Wistar rats submitted to different highfructose ingestion protocols. British Journal of Nutrition 101 1178-1184. (doi:10.1017/S0007114508066774)

Murarka S \& Movahed MR 2010 Diabetic cardiomyopathy. Journal of Cardiac Failure 16 971-979. (doi:10.1016/j.cardfail.2010.07.249)

Nunes S, Soares E, Fernandes J, Viana S, Carvalho E, Pereira FC \& Reis F 2013 Early cardiac changes in a rat model of prediabetes: brain natriuretic peptide overexpression seems to be the best marker. Cardiovascular Diabetology 12 44. (doi:10.1186/1475-2840-12-44)

Oron-Herman M, Kamari Y, Grossman E, Yeger G, Peleg E, Shabtay Z, Shamiss A \& Sharabi Y 2008 Metabolic syndrome: comparison of the two commonly used animal models. American Journal of Hypertension 21 1018-1022. (doi:10.1038/ajh.2008.218) 
Pfeiffer CM, Caudill SP, Gunter EW, Osterloh J \& Sampson EJ 2005 Biochemical indicators of B vitamin status in the US population after folic acid fortification: results from the National Health and Nutrition Examination Survey 1999-2000. American Journal of Clinical Nutrition $82442-450$

Porto LC, Sardinha FL, Telles MM, Guimaraes RB, Albuquerque KT, Andrade IS, Oyama LM, Nascimento CM, Santos OF \& Ribeiro EB 2009 Impairment of the serotonergic control of feeding in adult female rats exposed to intra-uterine malnutrition. British Journal of Nutrition 101 1255-1261. (doi:10.1017/S0007114508061503)

Ravelli AC, van Der Meulen JH, Osmond C, Barker DJ \& Bleker OP 1999 Obesity at the age of $50 \mathrm{y}$ in men and women exposed to famine prenatally. American Journal of Clinical Nutrition 70 811-816.

Schmidt MI, Duncan BB, Vigo A, Pankow JS, Couper D, Ballantyne CM, Hoogeveen RC \& Heiss G 2006 Leptin and incident type 2 diabetes: risk or protection? Diabetologia 49 2086-2096. (doi:10.1007/s00125-0060351-z)

Shan X \& Yeo GS 2011 Central leptin and ghrelin signalling: comparing and contrasting their mechanisms of action in the brain. Reviews in Endocrine \& Metabolic Disorders 12 197-209. (doi:10.1007/s11154-0119171-7)

Sie KK, Medline A, van Weel J, Sohn KJ, Choi SW, Croxford R \& Kim YI 2011 Effect of maternal and postweaning folic acid supplementation on colorectal cancer risk in the offspring. Gut 60 1687-1694. (doi:10.1136/ gut.2011.238782)

Sinclair KD, Allegrucci C, Singh R, Gardner DS, Sebastian S, Bispham J, Thurston A, Huntley JF, Rees WD, Maloney CA et al. 2007 DNA methylation, insulin resistance, and blood pressure in offspring determined by maternal periconceptional $\mathrm{B}$ vitamin and methionine status. PNAS 104 19351-19356. (doi:10.1073/pnas.0707258104)
Smith D Jr, Johnson M \& Nagy T 2009 Precision and accuracy of bioimpedance spectroscopy for determination of in vivo body composition in rats. International Journal of Body Composition Research 7 21-26.

Steegers-Theunissen RP, Obermann-Borst SA, Kremer D, Lindemans J, Siebel C, Steegers EA, Slagboom PE \& Heijmans BT 2009 Periconceptional maternal folic acid use of $400 \mu \mathrm{g}$ per day is related to increased methylation of the IGF2 gene in the very young child. PLOS ONE $\mathbf{4}$ e7845. (doi:10.1371/journal.pone.0007845)

Van Assche FA, Holemans K \& Aerts L 2001 Long-term consequences for offspring of diabetes during pregnancy. British Medical Bulletin 60 173-182. (doi:10.1093/bmb/60.1.173)

Vickers MH, Breier BH, Cutfield WS, Hofman PL \& Gluckman PD 2000 Fetal origins of hyperphagia, obesity, and hypertension and postnatal amplification by hypercaloric nutrition. American Journal of Physiology. Endocrinology and Metabolism 279 E83-E87.

Vige A, Gallou-Kabani C \& Junien C 2008 Sexual dimorphism in nonMendelian inheritance. Pediatric Research 63 340-347. (doi:10.1203/ PDR.0b013e318165b896)

Xita N \& Tsatsoulis A 2010 Fetal origins of the metabolic syndrome. Annals of the New York Academy of Science 1205 148-155. (doi:10.1111/j.17496632.2010.05658.x)

Yajnik CS, Deshpande SS, Jackson AA, Refsum H, Rao S, Fisher DJ, Bhat DS, Naik SS, Coyaji KJ, Joglekar CV et al. 2008 Vitamin B12 and folate concentrations during pregnancy and insulin resistance in the offspring: the Pune Maternal Nutrition Study. Diabetologia 51 29-38. (doi:10.1007/s00125-007-0793-y)

Yamauchi T, Kamon J, Minokoshi Y, Ito Y, Waki H, Uchida S, Yamashita S, Noda M, Kita S, Ueki K et al. 2002 Adiponectin stimulates glucose utilization and fatty-acid oxidation by activating AMP-activated protein kinase. Nature Medicine 8 1288-1295. (doi:10.1038/nm788)

Received in final form 12 December 2014 Accepted 18 December 2014
(C) 2015 Society for Endocrinology Printed in Great Britain 